\title{
Functional Expansion of Sensorimotor Representation and Structural Reorganization of Callosal Connections in Lower Limb Amputees
}

\author{
Elington L. Simões, ${ }^{1}$ Ivanei Bramati, ${ }^{2}$ Erika Rodrigues, ${ }^{2,3}$ Ana Franzoi, ${ }^{4}$ Jorge Moll, ${ }^{2,5}$ Roberto Lent, ${ }^{1,5}$ \\ and Fernanda Tovar-Moll ${ }^{1,2,5}$ \\ ${ }^{1}$ Institute of Biomedical Sciences, Federal University of Rio de Janeiro, Rio de Janeiro, Rio de Janeiro, Brazil 21941-920, ${ }^{2}$ D’Or Institute for Research and \\ Education (IDOR), Rio de Janeiro, Rio de Janeiro, Brazil 22281-100, ${ }^{3}$ Augusto Motta University Center (UNISUAM), Rio de Janeiro, Rio de Janeiro, Brazil \\ 21041-010, ${ }^{4}$ Brazilian Association for Rehabilitation, Rio de Janeiro, Rio de Janeiro, Brazil 22461-000, and ${ }^{5}$ National Institute for Translational \\ Neuroscience, Rio de Janeiro, Rio de Janeiro, Brazil 22941-920
}

Previous studies have indicated that amputation or deafferentation of a limb induces functional changes in sensory (S1) and motor (M1) cortices, related to phantom limb pain. However, the extent of cortical reorganization after lower limb amputation in patients with nonpainful phantom phenomena remains uncertain. In this study, we combined functional magnetic resonance (fMRI) and diffusion tensor imaging (DTI) to investigate the existence and extent of cortical and callosal plasticity in these subjects. Nine "painless" patients with lower limb amputation and nine control subjects (sex- and age-matched) underwent a 3-T MRI protocol, including fMRI with somatosensory stimulation. In amputees, we observed an expansion of activation maps of the stump in S1 and M1 of the deafferented hemisphere, spreading to neighboring regions that represent the trunk and upper limbs. We also observed that tactile stimulation of the intact foot in amputees induced a greater activation of ipsilateral S1, when compared with controls. These results demonstrate a functional remapping of S1 in lower limb amputees. However, in contrast to previous studies, these neuroplastic changes do not appear to be dependent on phantom pain but do also occur in those who reported only the presence of phantom sensation without pain. In addition, our findings indicate that amputation of a limb also induces changes in the cortical representation of the intact limb. Finally, DTI analysis showed structural changes in the corpus callosum of amputees, compatible with the hypothesis that phantom sensations may depend on inhibitory release in the sensorimotor cortex.

\section{Introduction}

Functional and structural plasticity are well recognized properties of the nervous system (Kaas, 1991; Pons et al., 1991), occurring after drastic injuries such as loss of body parts, as much as following subtle physiological input (Buonomano and Merzenich, 1998; Xerri et al., 1999). Limb amputation in humans is associated with the intriguing "phantom limb" sensations in the vast majority of cases.

To explain phantom limb phenomena, different hypotheses have been proposed, among them Melzack's "neuromatrix" (1990; 1999), by which an innate network produces a unique pattern of neural activity representing the construct of the self. Because this hard-wired signature cannot be updated, it would

Received Sept. 8, 2011; revised Dec. 2, 2011; accepted Dec. 28, 2011.

Author contributions: E.L.S., A.F., J.M., R.L., and F.T.-M. designed research; E.L.S., I.B., R.L., and F.T.-M. performed research; E.L.S., I.B., E.R., R.L., and F.T.-M. analyzed data; E.L.S., I.B., E.R., A.F., J.M., R.L., and F.T.-M. wrote the paper.

This work was funded by grants to R.L. from the Ministry of Science and Technology (Instituto Nacional de Neurociência Translacional), Brazilian Council for the Development of Science and Technology, and the Foundation for Research Support in the State of Rio de Janeiro.

Correspondence should be addressed to Dr. Fernanda Tovar-Moll, Instituto de Ciências Biomédicas da Universidade Federal do Rio de Janeiro, Centro de Ciências da Saúde, BI. F, Cidade Universitária, CEP 21941-920, Rio de Janeiro, Brazil. E-mail: fernanda.tovarmoll@idor.org.

DOI:10.1523/JNEUROSCI.4592-11.2012

Copyright $\odot 2012$ the authors $\quad 0270-6474 / 12 / 323211-10 \$ 15.00 / 0$ remain unchanged even after amputation, generating the perceptual conflicts referred as the phantom-limb syndrome (Doetsch, 1997; Reilly and Sirigu, 2008).

Previous studies have shown that limb amputation or deafferentation induces changes in primary sensory (S1) and motor (M1) cortices (reviewed by Chen et al., 2002), with evidence deriving from electroencephalography (Flor et al., 2000; Grüsser et al., 2001; Karl et al., 2001), transcranial magnetic stimulation (TMS) (Cohen et al., 1991; Pascual-Leone et al., 1996; Röricht et al., 1999; Mercier et al., 2006), magnetoencephalography (Flor et al., 1995), and functional magnetic resonance imaging (fMRI) (Lotze et al., 1999; Giraux et al., 2001; Grüsser et al., 2004). A remapping of cortical topography in upper limb amputees is consistently found, with enlargement and increased activation of the S1/M1 face area after stump stimulation (Ramachandran et al., 1992; Karl et al., 2001). These changes have been associated with phantom phenomena, especially pain (Flor et al., 1995; Flor, 2002), implying that nonpainful phantom phenomena might not be associated with somatomotor plasticity (Karl et al., 2001, Lotze et al., 2001). Nevertheless, although phantom pain is seldom directly tested, and some authors deal with plasticity without pain (Giraux et al., 2001; Vargas et al., 2009), most focus on upper limb amputees who report phan- 
Table 1. Demographic details of the amputees

\begin{tabular}{ll}
\hline Patients $(n=9)$ & \\
Male/female & $5 / 4$ \\
Age in years (mean \pm SD) & $32.9 \pm 8.9$ \\
Age at amputation in years (mean \pm SD) & $15.3 \pm 5.9$ \\
Time since amputation in years (mean \pm SD) & $17.3 \pm 9.9$ \\
Side of amputation (left/right) & $6 / 3$ \\
Level (transtibial/transfemoral) & $3 / 6$ \\
Prosthesis (cosmetic/none) & $3 / 6$ \\
Cause of amputation (traumatic/oncologic) & $8 / 1$ \\
Phantom limb (permanent/intermittent) & $5 / 4$ \\
\hline
\end{tabular}

tom pain (Ramachandran, 1993; Flor et al., 1998; Lotze et al., 1999, 2001; MacIver et al., 2008).

In animals, reorganization was shown at multiple loci, from cortex to spinal cord (Pons et al., 1988; Merzenich and Jenkins, 1993; Nicolelis et al., 1993; Florence and Kaas, 1995; Wu and Kaas, 2000). In humans, emphasis was given to the cortex (Chen et al., 1998; Werhahn et al., 2002a,b), although a contribution of subcortical structures cannot be overlooked (Tanaka et al., 2008; Curt et al., 2011). Cortical phenomena were explained by reduced GABAergic inhibition (Werhahn et al., 2002a) involving different GABA receptors (Garraghty et al., 2006), and other transmitters as well (Juliano et al., 1991).

We combined fMRI and diffusion tensor imaging (DTI) to investigate cortical and callosal plasticity in lower limb amputees with "painless" phantom sensations, to clarify whether plastic phenomena can be generalized beyond upper limb amputation with phantom pain, and to test whether they could be related to callosal dis(re)organization. We found that the deafferented hemisphere shows an overlapping, expanded representation of the stump (after stump stimulation) and of the intact limb (after its stimulation), and that structural changes do occur in somatomotor sectors of the corpus callosum.

\section{Materials and Methods}

Participants. Nine lower limb amputees without phantom pain participated in the study (five men and four women averaging 32.9 years old; range 18-41 years), eight amputated after traumatic injury, one due to osteosarcoma. Subjects underwent a comprehensive standard neurological examination and an interview with detailed assessments of their phantom sensations, including telescoping, distorted perception of the phantom limb, abnormal postures, and illusory phantom limb displacement. Exclusion criteria for the study were a history of neurological disease, diabetes, recent or past neurosurgical intervention, previous neurotrauma, psychotropic medication, or MRI contraindication. Nine healthy individuals matched for age and sex (mean age 31.6 $\pm 9.1 \mathrm{SD}$; range 18-41 years) served as healthy controls. Patients' characteristics are summarized in Table 1 . All participants signed a written informed consent for the study and the protocol was approved by the Ethics Committee of our institution and performed according to international standards (Declaration of Helsinki, 2000).

Neuroimaging. All subjects underwent image acquisition in a $3 \mathrm{~T}$ magnetic resonance scanner (Achieva, Philips Medical Systems), which included the following sequences: turbo spin echo T2-weighted, fluid attenuated inversion recovery (FLAIR), volumetric high-resolution 3D turbo field-echo T1-weighted sequence (TR, $13 \mathrm{~s}$; TE, $1.4 \mathrm{~s}$; Matrix, $256 \times 356$; FOV, $240 \mathrm{~mm}$; slice thickness, $1 \mathrm{~mm}$; 140 slices), DTI and functional magnetic resonance imaging (fMRI). Head motion was restricted by using foam padding and straps over the forehead and under the chin (estimated translation and rotation parameters were inspected and never exceeded $2 \mathrm{~mm}$ or $2^{\circ}$ ). Images were laterally flipped for three patients with right side amputation to simplify comparisons with the other amputees. This procedure has been used successfully by other investigators (Diers et al., 2010). Therefore, for imaging analysis in amputees, the right brain hemisphere was considered contralateral to amputation, while the left hemisphere was considered ipsilateral to amputation. In addition, although it is possible that a limb amputation can induce reorganization and changes in both brain hemispheres due to deafferentation, to make the description of the analyses and results more straightforward and clear, the hemisphere contralateral to amputation is referred to here as deafferented hemisphere.

Diffusion-weighted images. Diffusion-weighted images were acquired in the axial plane using a single-shot, spin-echo, echoplanar sequence, with an isotropic voxel size of $2 \mathrm{~mm}^{3}$ (60 slices: TR/TE, 7943/60 ms; FOV, $232 \mathrm{~mm}$; matrix, $116 \times 116$; slice thickness, $2.0 \mathrm{~mm} /$ no gap). Diffusion sensitization gradients were applied in 32 noncollinear directions, with a $\beta$ factor of $1000 \mathrm{~s} / \mathrm{mm}^{2}$.

Functional images. Functional images were acquired using a $\mathrm{T} 2{ }^{\star}$ weighted, single-shot, fast field echo, echoplanar (blood oxygenationlevel-dependent contrast) sequence (TR/TE, 2000/35 ms; Matrix, $96 \times$ 96; FOV, $230 \mathrm{~mm}$; flip angle, $90^{\circ}$; slice thickness, $4 \mathrm{~mm}$; 24 slices; 100 volumes acquired in a single run). Total functional scanning time was $\sim 3$ min and $40 \mathrm{~s}$, for each functional assessment. Before each run, five dummy volumes were collected to allow longitudinal magnetization equilibrium to be attained (global signal intensity stabilization). A "dynamic stabilization" method was additionally used to improve image consistency across dynamic scans (Benner et al., 2006). The fMRI protocol was performed in a block design fashion: each block contained two experimental conditions (relaxation and stimulation) and 10 dynamic scans for each condition. Each block was repeatedly acquired five times during the experiment, totalizing 100 dynamic scans.

The participants were instructed to stay relaxed and still during the experiment. During each functional assessment, a nonpainful cutaneous tactile stimulus $(5-6 \mathrm{~Hz})$ was applied with a soft brush over an area of $10 \times 2 \mathrm{~cm}$ (Condés-Lara et al., 2000). For amputees, the stimulation was delivered at $2 \mathrm{~cm}$ of the stump end (hereafter called "stump"); on the intact limb at the same level of amputation ("intact limb homologue"); and over the dorsal aspect of the remnant halux and foot ("intact foot"). The paired controls received the stimulation on the same region corresponding to the level of amputation ("control stump homologue") and over the dorsal aspect of both halux and feet ("control foot").

Image preprocessing. Before image analysis, subjects' datasets were anonymized and randomized across the subjects and groups. For each subject and before estimating the specific diffusion or functional maps, all images were visually inspected for artifacts.

fMRI processing. Statistical Parametric Mapping (SPM8 software package; www.fil.ion.ucl.ac.uk/spm/software/spm8) and the general linear model (GLM) were used for image analysis (Friston et al., 1995; Worsley and Friston, 1995). All functional datasets were first realigned by registering each dynamic scan to the first acquired volume, using a rigid-body algorithm, spatially normalized into MNI (Montreal Neurological Institute) standard space, with a $2 \times 2 \times 2$ isotropic resolution, and smoothed using an $8 \mathrm{~mm}$ FWHM Gaussian spatial kernel filter. Cubic detrending was used to remove unwanted low frequencies from the fMRI time series (Macey et al., 2004).

The activation of sensory maps, with emphasis on S1, were individually calculated by means of parametric statistical voxel-by-voxel analysis, to describe the data in terms of experimental effects and residual variability, in combination with a temporal convolution modeled to a hemodynamic response function. Classical statistical inference is used to test hypotheses that are expressed in terms of GLM parameters, represented by SPM.

To create maps of sensory activation, representing the difference between patients and controls, statistical effects were calculated on the second level by using the continuous random field theory model. Significant brain activation effects were reported using either (1) voxel-level family wise error (FWE) correction over the whole brain, at $p<0.05$ corrected for multiple comparisons, or (2) an uncorrected $p=0.001$, for visualization purposes or to explore effects in a priori regions (S1 and M1).

Diffusion-weighted image processing. The diffusion tensor for each voxel was calculated based on the eigenvectors $(\mathrm{v} 1, \mathrm{v} 2, \mathrm{v} 3)$ and eigenvalues $(\lambda 1, \lambda 2, \lambda 3)$ using multivariate fitting and diagonalization (Pajevic and Pierpaoli, 1999; Jiang et al., 2006). After the fractional anisotropy 

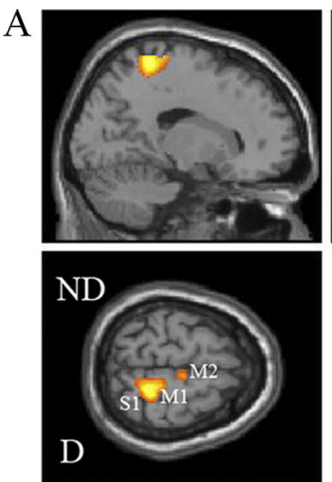

stump
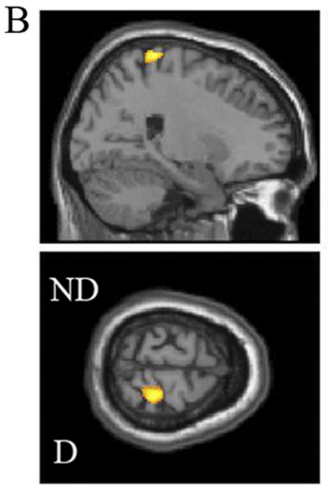

controls stump homologue
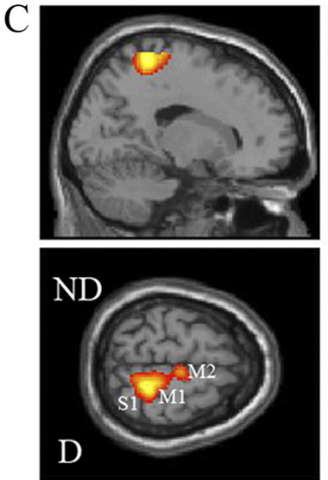

stump
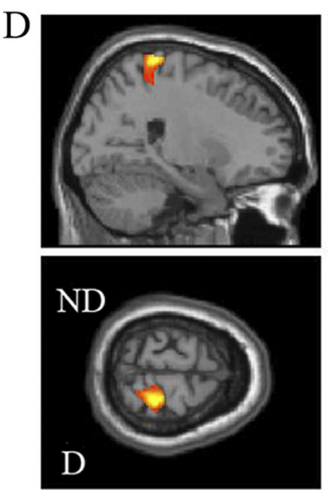

controls stump homologue

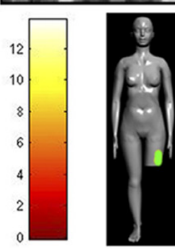

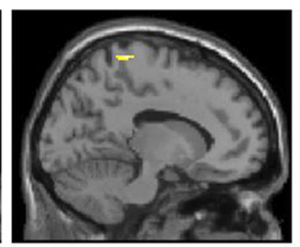
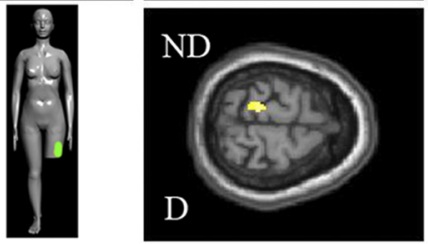

intact foot
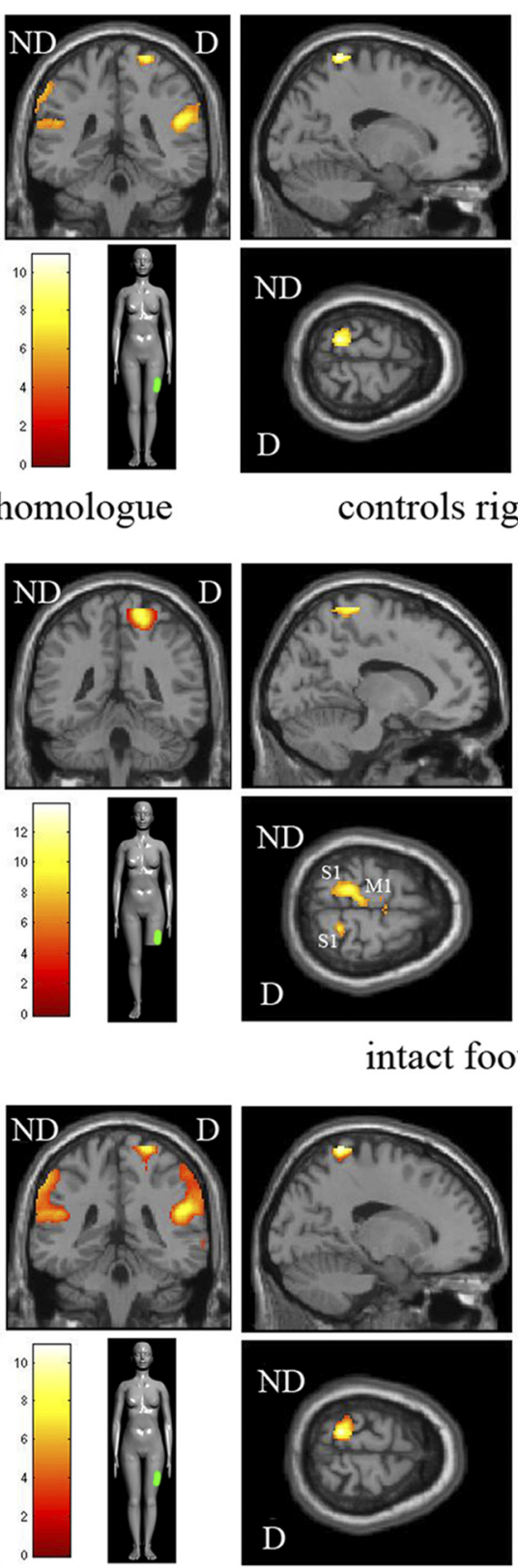

controls right foot
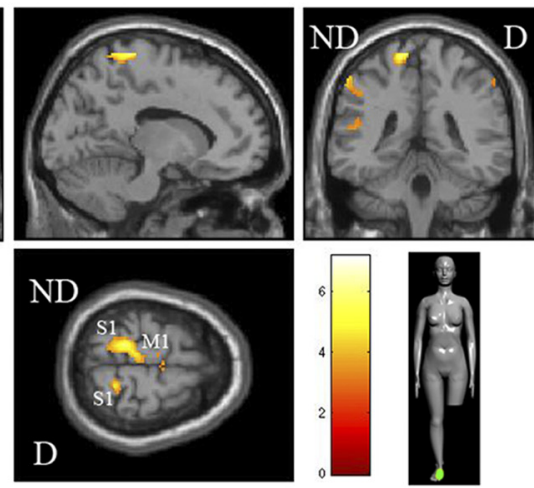

intact foot
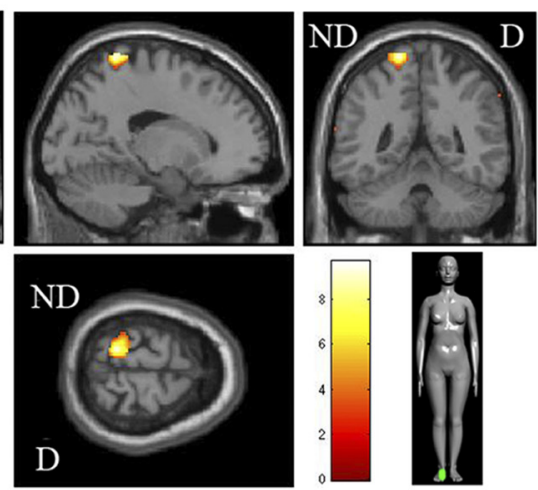

controls right foot
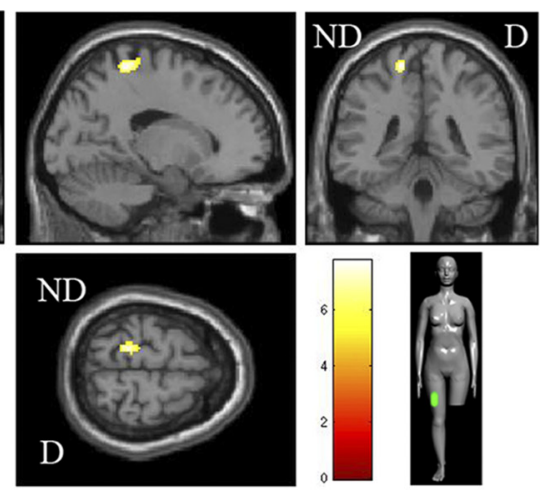

intact limb homologue
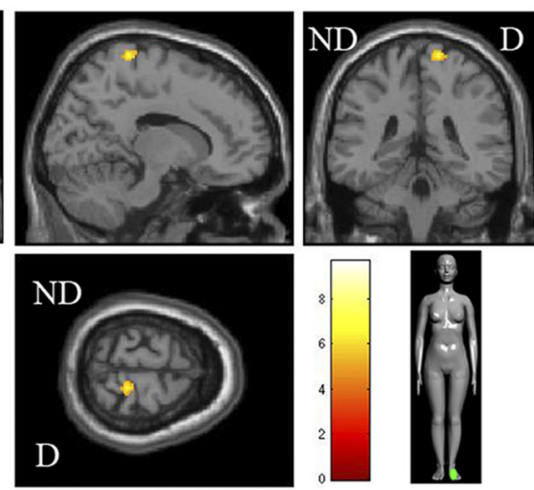

controls left foot
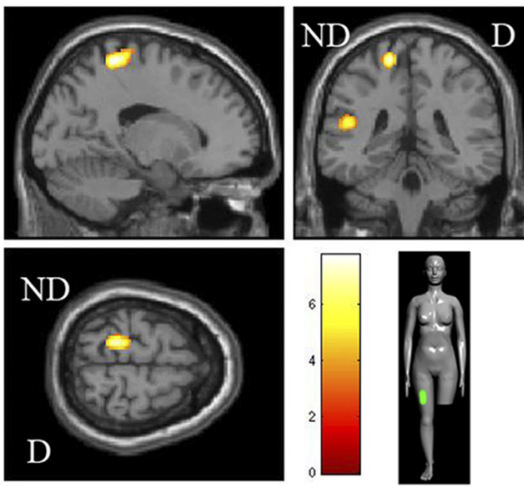

intact limb homologue
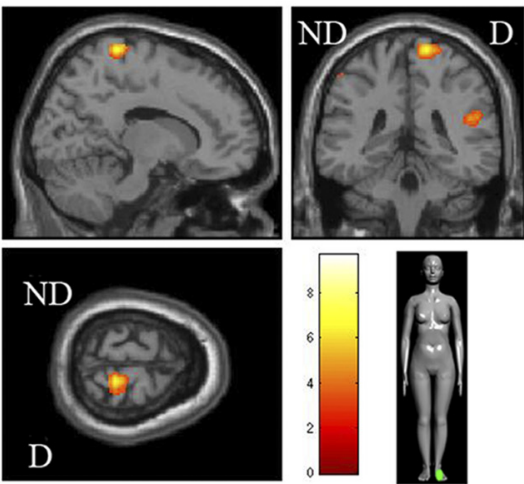

controls left foot

Figure 1. Activation maps during tactile stimulation. $\boldsymbol{A}, \boldsymbol{C}$, Amputees, corrected and uncorrected data (thresholded at $p<0.05$ and $p<0.001$, respectively). $\boldsymbol{B}, \boldsymbol{D}$, Healthy controls, corrected and uncorrected data (thresholded at $p<0.05$ and $p<0.001$, respectively). Note the expansion of stump representation in S1 contralaterally, and the appearance of a sizeable tactile activation in contralateral M1 and M2. ND, nondeafferented hemisphere; D, deafferented hemisphere. 
A
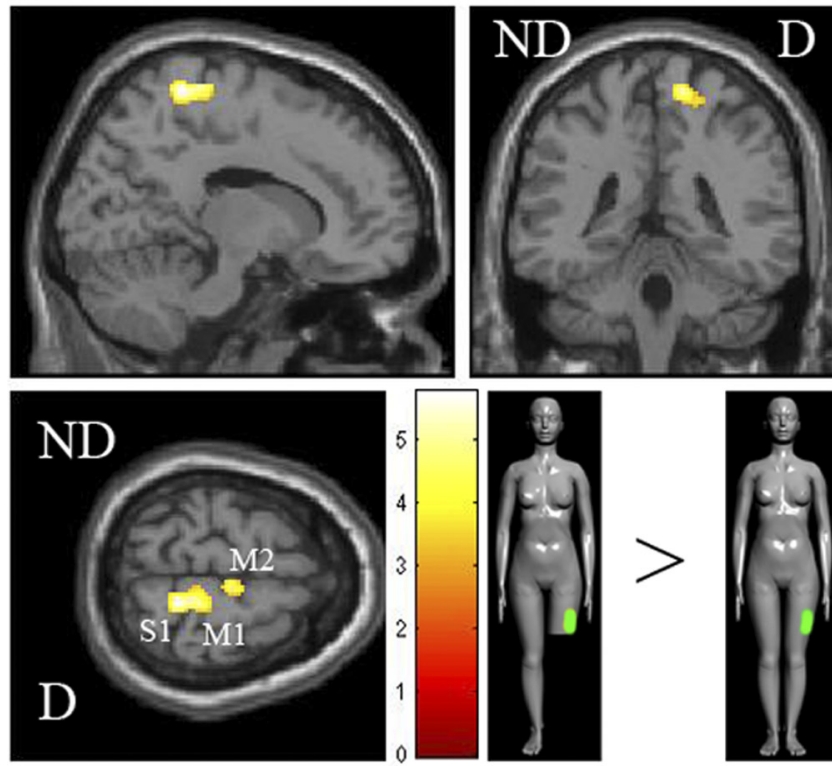

stump $>$ control stump homologue

$\mathrm{C}$
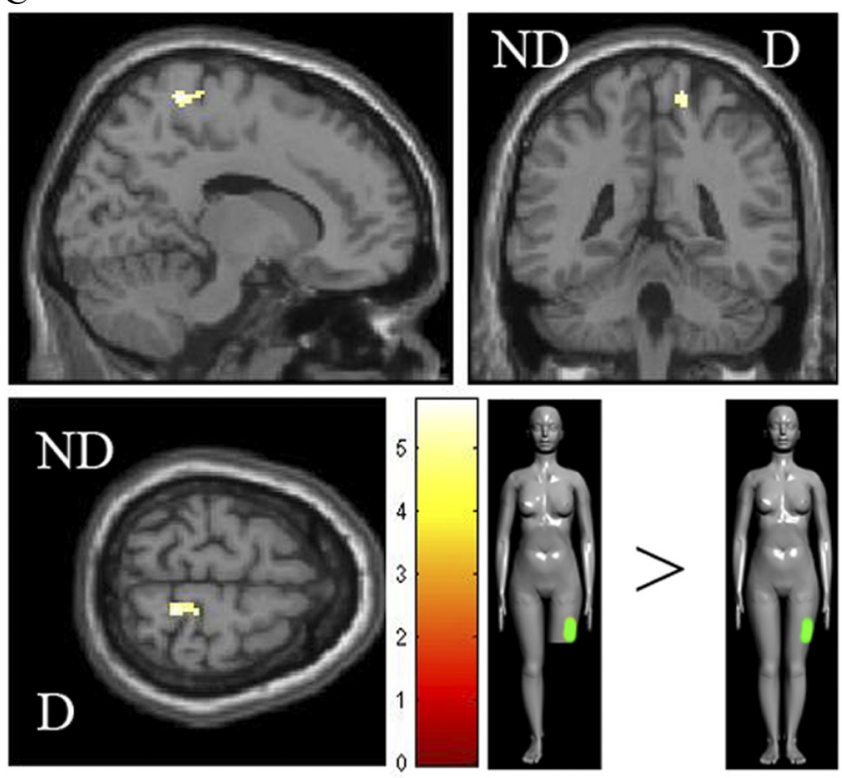

\section{stump $>$ control stump homologue}

B
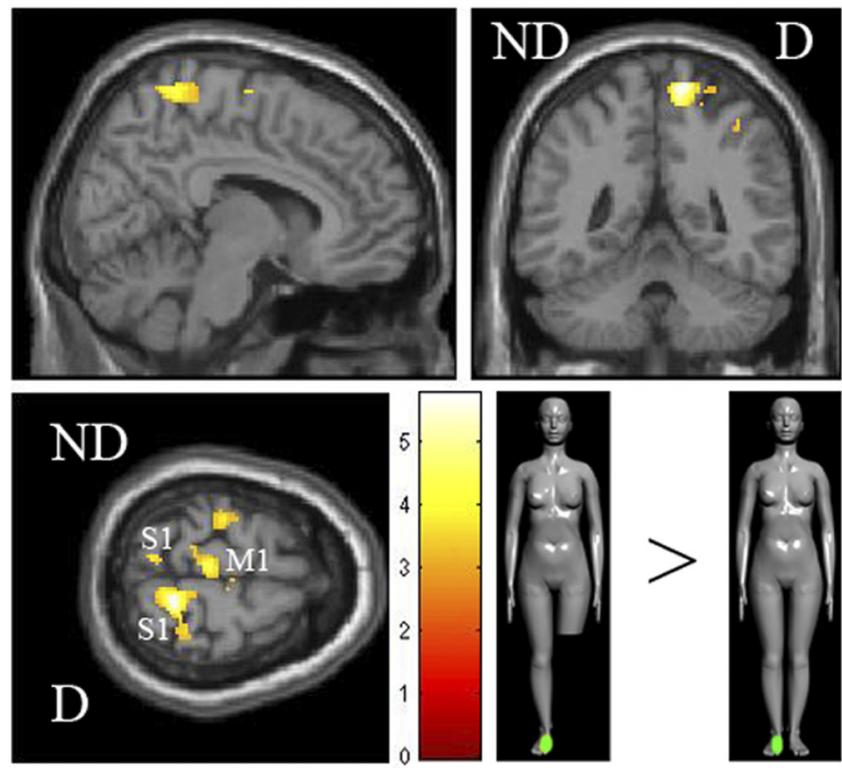

intact foot $>$ control foot

$\mathrm{D}$
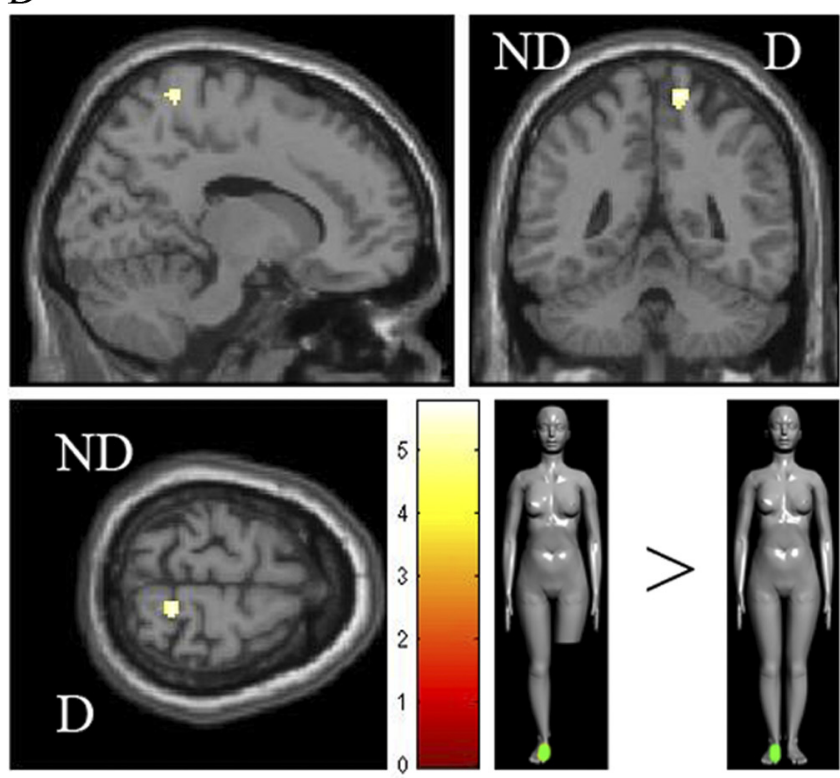

intact foot $>$ control foot

Figure 2. Comparisons between amputees and controls. $\boldsymbol{A}, \boldsymbol{C}$, Expanded sensorimotor cortical activations of the stump in amputees when compared with control homologue; $\boldsymbol{B}, \boldsymbol{D}$, Increased and bilateral activations in response to stimuli on the intact foot of amputees when compared with control foot. $\boldsymbol{A}, \boldsymbol{B}, p<0.001$, uncorrected; $\boldsymbol{C}, \boldsymbol{D}, p<0.05$, corrected). Abbreviations are as defined in the legend to Figure 1.

(FA) maps were calculated from the eigenvalues, color-coded maps were generated from the FA values and three vector elements of $\mathrm{v} 1$ to visualize the white matter tract orientation (DTIFit 2.0, FDT-FMRIB's Diffusion Toolbox, FSL Software Library). FA images were brain-extracted (BET 2.1-Brain Extraction Tool, FSL Software Library; Smith, 2002) and registered to a common space (MNI152), using constrained nonlinear registration (Image Registration Toolkit; Rueckert et al., 1999). The derived FA data were further analyzed using two approaches: (1) a priori region of interest (ROI) analysis (Jiang et al., 2006; Tovar-Moll et al., 2009), and (2) a voxelwise whole-brain tract-based spatial statistics analysis (TBSS 1.2, FSL Software Library; Smith et al., 2006; Simonyan et al., 2008). Nondiffusion and diffusion images were coregistered to correct for movement artifacts and eddy current distortion effects on EPI readout.
DTI voxelwise whole-brain analysis. To assess the global differences in the white matter fiber tracts between the patients and healthy controls, whole-brain voxelwise statistical analyses of FA data were conducted using TBSS (Smith et al., 2004).

To preserve the original white matter structure, keeping the overall tracts intact as much as possible, a voxelwise specifically tuned nonlinear registration method was used to align FA images of all subjects into a standard space (Image Registration Toolkit, Rueckert et al., 1999). FA images of all subjects were aligned to the first subject FA image, acting as the reference target FA; this target image is then affine-aligned into MNI152 standard and upsampled to $1 \times 1 \times 1 \mathrm{~mm}$ (using both the nonsegmented and segmented $1 \times 1 \times 1 \mathrm{~mm}$ MNI152 T1 brain volume); then, both the nonlinear and affine transformations from the target im- 
Table 2. Coordinates of cluster centroids (voxel maxima)

\begin{tabular}{|c|c|c|c|c|c|c|c|c|}
\hline Group & Stimulus & $\begin{array}{l}\text { Cortical } \\
\text { area }\end{array}$ & Hemisphere & $x$ & $Y$ & Z & $t$ & $z$ value \\
\hline \multirow{5}{*}{ Amputees } & Stump & S1 & Deafferented & 18 & -42 & 66 & 11.15 & $>8$ \\
\hline & Stump & M1 & Deafferented & 14 & -35 & 68 & 11.15 & $>8$ \\
\hline & Stump & M2 & Deafferented & 6 & -16 & 68 & 7.01 & 6.91 \\
\hline & Intact foot & S1 & Nondeafferented & -12 & -36 & 72 & 6.37 & 6.29 \\
\hline & Intact limb homologue & S1 & Nondeafferented & -16 & -40 & 66 & 7.73 & 7.59 \\
\hline \multirow[t]{3}{*}{ Controls } & $\begin{array}{l}\text { Controls stump } \\
\text { homologue }\end{array}$ & S1 & Deafferented & 24 & -38 & 74 & 8.30 & $>8$ \\
\hline & Right foot & S1 & Nondeafferented & -16 & -46 & 74 & 9.16 & $>8$ \\
\hline & Left foot & S1 & Deafferented & 14 & -38 & 74 & 6.58 & 6.49 \\
\hline
\end{tabular}

Cortical area activations during cutaneous tactile stimuli ( $X, Y, Z$ are MNI coordinates; $p<0.05$, corrected).

Table 3. Coordinates of cluster centroids (voxel maxima) for group contrasts

\begin{tabular}{|c|c|c|c|c|c|c|c|}
\hline Group contrasts & $\begin{array}{l}\text { Cortical } \\
\text { area }\end{array}$ & Hemisphere & $x$ & $Y$ & Z & $t$ & $z$ value \\
\hline $\begin{array}{l}\text { Stump }>\text { controls stump } \\
\text { homologue }\end{array}$ & S1 & Deafferented & 14 & -42 & 68 & 5.76 & 5.73 \\
\hline $\begin{array}{l}\text { Stump }>\text { intact limb } \\
\text { homologue }\end{array}$ & S1 & Deafferented & 12 & -54 & 64 & 6.68 & 6.63 \\
\hline $\begin{array}{l}\text { Stump }>\text { intact limb } \\
\text { homologue }\end{array}$ & S1 & Nondeafferented & -20 & -60 & 64 & 5.56 & 5.54 \\
\hline $\begin{array}{l}\text { Intact foot }>\text { controls right } \\
\quad \text { foot }\end{array}$ & S1 & Deafferented & 14 & -46 & 70 & 5.84 & 5.81 \\
\hline
\end{tabular}

Cortical area activations during cutaneous tactile stimuli $(X, Y, Z$ are MNI coordinates; $p<0.05$, corrected).

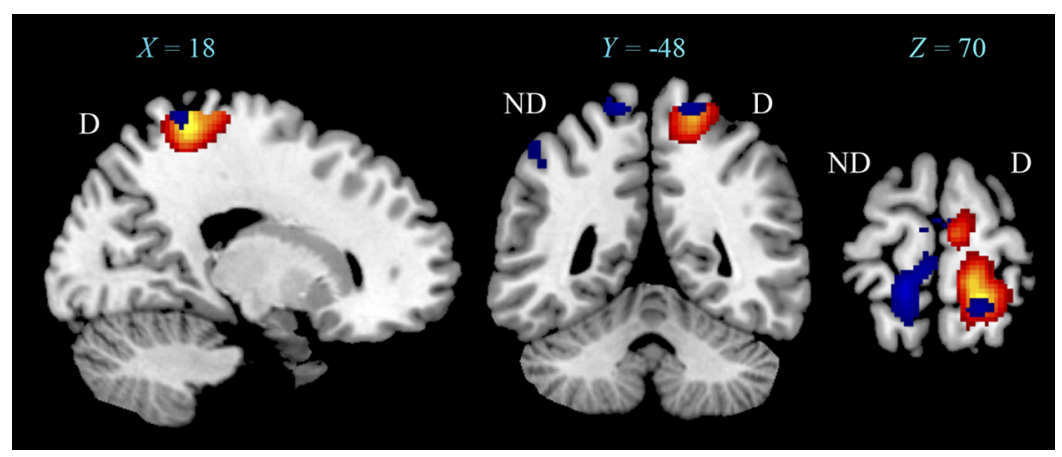

Figure 3. Cortical activation overlays representing amputees stump (yellow/orange) and intact foot (blue). Note the overlap on the hemisphere contralateral to amputation on deafferented hemisphere ( $X, Y, Z$ are MNI coordinates; $p<0.001$, uncorrected). Abbreviations are as defined in the legend to Figure 1.

age were applied to each FA subject's images. All upsampled aligned FA images were averaged to create the mean FA for all subjects. The mean FA was used to generate the "skeleton" tract, which represents those tracts documented in all subjects (Smith et al., 2006). These tracts were thresholded to restrict the statistical analysis only to the white matter voxels which are successfully aligned across subjects, maintaining only the subject's major tract structures in further analyses. Finally, each subject's aligned FA data were "projected" into the mean FA skeleton mask, generating the final projected "skeletonized" FA data (Smith et al., 2006).

To test for significant local FA differences between groups, considering the body of the corpus callosum (CC) and the whole brain, a voxelwise cross-subject statistical analysis was performed using permutation-based nonparametric inference (10,000 random permutations) on each voxel of the resulting "skeletonized" subject's data (Nichols and Holmes, 2002). The statistical images were then thresholded at $p<0.01$ uncorrected, and $p<0.05$ corrected for multiple comparisons (using FWE). The final thresholded-skeletonized resulting image was thickened to better visualization.

Body of the corpus callosum FA quantification. To evaluate the microstructural integrity of the CC in amputees compared with controls, measures of diffusion anisotropy were evaluated within the callosal body.
Parcellation of the CC was performed based on a DTI-MRI atlas of human white matter (ICBM DTI-81 stereotaxic probabilistic white matter atlas). The ROI was automatically loaded onto the "skeletonized" FA map for each subject and visually checked to confirm their location. The mean value of FA measure within the body of the CC was automatically extracted (FSL 4.1, FMRIB software). These DTI measures were statistically compared between amputees and controls using a nonparametric test (Mann-Whitney). Statistical significance was assumed at a threshold of $p<0.05$.

Fiber tracking. For fiber tracking, Bayesian Estimation of Diffusion Parameters, with crossing fibers modeling (BEDPOSTX, FSL Software Library), was used to build up distributions of diffusion parameters at each voxel (Markov Chain Monte Carlo sampling technique). It creates all necessary files for running probabilistic tractography and allows modeling and determining the number of crossing fibers within each voxel on the whole brain (Behrens et al., 2007).

First, original individual FA maps were registered to the FA template in the MNI space (FMRIB58 FA template), using a nonlinear registration tool (FNIRT, FSL Software Library). Then, a ROI was placed at the presumed callosal somatosensory area according to a JHU (Johns Hopkins University) FA atlas, after topographical segmentation of the corpus callosum (Hofer and Frahm, 2006). To spatially adapt the minor morphological differences between the callosal sector of interest of each subject, the JHU FA atlas with the callosal ROI was inversely transformed into native space based on subjects nonlinear registration parameters. Probabilistic tractography was then performed (PROBTRACKX, FSL Software Library) in the native space of each subject, as described.

To investigate possible differences in callosal fiber topography induced by amputation, a sequence of single voxel ROI tractography was performed in each subject. Five points were selected along the somatosensory callosal sector and the fiber termination distance from brain midline was calculated for each subject. Fiber connectivity topography was compared between brain hemispheres and between amputees and controls. These measures were compared between amputees and controls using the Mann-Whitney test. Statistical significance was assumed at a threshold of $p<0.05$.

\section{Results}

Conventional MRI (FLAIR, T1- and T2weighted images) showed no abnormalities in the brains of amputees and controls. In contrast, fMRI and DTI revealed clear functional and white matter microstructural changes in amputees. None of the patients reported pain during tactile stimulation on prescanning or postscanning interview.

\section{Expanded cortical representation of the stump}

In amputees, sensory stimulation of the stump resulted in activation of S1 and M1 contralateral to the amputation (deafferented hemisphere), in addition to the supplementary motor area (M2; Fig. $1 A, C)$. Other significant activation sites were bilateral S2, bilateral insula and thalamus and striatum in the hemisphere contralateral to the amputation (data not shown). In some amputees (cases $4-7$ ), analysis of individual data showed activation of S1 foot/leg representation area in the hemisphere ipsilateral to the stump.

As expected, stimulation of a corresponding stump region in controls (control stump homologue) evoked activation in the contralateral S1 leg/foot representation, bilateral S2, and insula (Fig. $1 B, D$ ). The striatum was activated as well (data not shown). No activation was observed in M1 and/or M2 or in S1 ipsilateral to the stimuli in controls in any of the experimental situations. 
By group contrast, it was possible to compare the cortical representation of the stump in amputees, with the homologous leg region in controls. This comparison revealed increased activation and topographic expansion of the stump representation located in S1, M1, and M2 contralateral to the amputation (Fig. 2A). After correction for multiple comparisons, increased stump representation located in $\mathrm{S} 1$ proved significant (Fig. 2C).

Cutaneous tactile stimuli and corresponding cortical activations coordinates for both groups are depicted on Table 2. Cluster centroid coordinates ("voxel maxima") representing differences between amputees and controls are depicted on Table 3.

\section{Expanded cortical representation of the} intact limb

In amputees, stimulation of the intact foot and homologous region (homologous to the stump) resulted in activation of $\mathrm{S} 1$ contralateral to the stimuli (Fig. $1 A, C$ ).

Furthermore, Figure $1 C$ shows additional activation in $\mathrm{M} 1$ contralateral and in S1 ipsilateral (in deafferented hemisphere) when the intact foot was stimulated in amputees.

Figure $1 B, D$ shows activations of $S 1$ contralateral to the stimuli when right or left foot was stimulated in controls. In contrast to amputees, no activation was observed in M1 or in S1 ipsilateral to the stimuli in controls in any of the experimental situations.

When tactile stimulation of the intact foot of amputees was compared with stimulation of the same region in controls (control foot), an increased representation was observed in amputees. Stimulation of the intact foot induced a greater activation of bilateral S1 and M1 contralateral to the stimuli, when compared with controls (Fig. $2 \mathrm{~B}$ ). In amputees, the increased representation of the intact foot at S1 ipsilateral to the stimuli (that is, at the deafferented hemisphere) survived after multiple-comparisons correction (Fig. 2D).

It is noticeable that the deafferented hemisphere shelters an overlapping, expanded representation of the stump and the intact limb, suggesting that the same cortical region of amputees is now processing different body parts (Fig. 3).

\section{Microstructural changes of the corpus callosum}

DTI voxelwise analysis of the body of the corpus callosum showed reduced FA values bilaterally in amputees compared with controls (Fig. 4A). This finding was specific, since voxelwise whole-brain analysis revealed a single region on the same topography (Fig. $4 B$ ).

\section{Displacement of callosal connections in amputees}

Adopting a single voxel as an initial seed for fiber tracking, we attempted to determine the topography of the callosal fibers which project to the primary sensory cortex in amputees and controls.

As shown in Table 4, a lateral displacement ( $x$-axis) of callosal terminations reaching the primary sensory cortex was found in the hemisphere contralateral to the amputation (the deafferented hemisphere) when amputees were compared with controls $(p<$ $0.026)$. In amputees, a rostrocaudal displacement ( $z$-axis) of the same group of fibers was also observed in the hemisphere ipsilateral to the amputation $(p<0.009)$.

To investigate a possible increase in heterotopy of amputees' callosal fibers (i.e., callosal fibers connecting nonhomotopic cortical regions), the distance of callosal terminations in the sensory cortex to the brain midline was computed in each hemisphere of amputees. We found a symmetrical distribution of callosal sensory fibers in each hemisphere of amputees, and a similar distribution was found in controls as well.

\section{Discussion}

The terms phantom limb and phantom sensation are used to define the illusion that virtually all amputees report, that their absent limb or body part is still present, evoking different somatosensory submodalities as light touch, heat, itch, pain, and others (Ramachandran et al., 1992; Ramachandran and Hirstein, 1998; Chahine and Kanazi, 2007; Casale et al., 2009). Phantom pain has been related to sensorimotor reorganization in the cerebral cortex contralateral to amputation (Flor, 2003; MacIver et al., 2008), and is believed to originate from unmasking of pre-existing circuits due to removal or inactivation of inhibitory synapses (Ramachandran and RogersRamachandran, 2000), or following changes in callosal connections (Schwenkreis et al., 2003; Giummarra et al., 2007). Cortical reorganization related to nonpainful phantom sensation in amputees, however, has remained controversial (Flor et al., 2006).

We here reported functional and structural brain reorganization in lower limb amputees with nonpainful phantom sensations. Functional MRI revealed an expansion of activation maps of the stump sensory representation in the postcentral gyrus of the deafferented hemisphere, encompassing the putative representations of the trunk and upper limbs, invading also the lower limb representation in the precentral gyrus. We also showed that tactile stimulation of the intact leg and foot of amputees induces a greater activation of ipsilateral S1, suggesting that amputation also determines changes in the cortical representation of the intact limb. Additionally, DTI 
Table 4. Displacement of callosal connections in amputees

\begin{tabular}{|c|c|c|c|c|c|c|}
\hline & \multicolumn{3}{|c|}{ Deafferented hemisphere } & \multicolumn{3}{|c|}{ Nondeafferented hemisphere } \\
\hline & $x$-axis displacement & $y$-axis displacement & z-axis displacement & $x$-axis displacement & $y$-axis displacement & z-axis displacement \\
\hline Mann-Whitney U & 467.000 & 658.500 & 508.000 & 596.500 & 607.000 & 434.500 \\
\hline Wilcoxon W & 1370.000 & 1186.500 & 1036.000 & 1499.500 & 1273.000 & 1100.500 \\
\hline$Z$ & -2.247 & -0.147 & -1.792 & -1.602 & -1.495 & -3.228 \\
\hline$p$ value & 0.026 & 0.883 & 0.073 & 0.109 & 0.135 & 0.009 \\
\hline
\end{tabular}

analysis showed structural changes in the corpus callosum of amputees, which could be related to decreased inhibition mediated by this commissure.

\section{Functional reorganization related to nonpainful phantom phenomena}

The phantom phenomenon is perceived as a vivid experience in up to $98 \%$ of amputees, most commonly after loss of a limb (Ramachandran et al., 1992; Knecht et al., 1998; Ramachandran and Hirstein, 1998; Giummarra et al., 2007). However, phantom sensations have also been reported after mastectomy (Staps et al., 1985; Björkman et al., 2008), testis resection (Pühse et al., 2010), teeth extraction (Marbach, 1978), eye enucleation (Sörös et al., 2003), and even surgical removal of internal organs (Dorpat, 1971; Arcadi, 1977; Ovesen et al., 1991).

Since the demonstration of cortical somatosensory map reorganization in peripherally deafferented adult primates (Merzenich et al., 1984; Pons et al., 1991) and rats (Donoghue et al., 1990; Sanes et al., 1990), attention was turned to mechanisms that could explain phantom sensations in humans, presuming that they might be perceptual correlates of cortical reorganization after amputation (Ramachandran et al., 1992; Flor et al., 1995; Montoya et al., 1997; Grüsser et al., 2004). Most studies in upper limb amputees with phantom pain claim that it would be a correlate of functional remapping within the deafferented cortex (Ramachandran, 1993; Birbaumer et al., 1997; Borsook et al., 1998; Flor et al., 1998; Montoya et al., 1998; Lotze et al., 1999; Dettmers et al., 2001; Grüsser et al., 2001; Karl et al., 2001; Lotze et al., 2001; MacIver et al., 2008). The more intense the phantom pain, the more extensive the remapping observed in somatosensory and motor cortex (Flor et al., 2006). According to this view, nonpainful sensations would be a less prominent marker of somatosensory plasticity (Karl et al., 2001; Flor et al., 2006), although studies showing cortical reorganization after deafferentation in nonhuman primates do report morphological and electrophysiological plasticity but not behaviors that could suggest the occurrence of phantom pain (Florence and Kaas, 1995; Darian-Smith and Brown, 2000).

Our study demonstrated that cortical reorganization also exists in lower limb amputees, even in the absence of phantom limb pain. We observed an expansion of S1 stump representation into neighboring somatosensory areas and primary motor cortex contralateral to amputation. Moreover, plasticity in amputees was found to be bilateral. It seems, therefore, that the deafferented cortex receives an overlapping, incongruent representation in its territory, encompassing the stump (enlarged) and the intact limb. This functional overlap might contribute to the appearance of phantom phenomena.

It is known that $\mathrm{S} 1$ includes four architectonic fields, histologically and physiologically distinct, each containing a separate body representation (reviewed by Kaas, 1983). The cutaneous (exteroceptive) stimuli applied to our subjects, therefore, should activate mainly areas $3 \mathrm{~b}$ and 1 . Therefore, one could wonder whether the functional changes herein reported would reflect homogenous or distinct plastic changes among the areas comprising S1, as reported by Qi et al. (2011). Investigating this more refined aspect, however, was not the main goal of the present study, and would require a high-resolution fMRI approach specifically focusing on the postcentral gyrus.

In agreement with our findings, TMS and fMRI in upper limb amputees (Hamzei et al., 2001) showed an enlargement of the stump representation in the deafferented cortex, plus a functional reorganization in the nondeafferented hemisphere. They also found structural deformities of both central sulci in some patients and an atrophic contralateral parietal lobule in others, suggesting bilateral functional and anatomical reorganization in these subjects.

We also observed bilateral activation of S2 during stimulation of the stump, of the intact foot, and of the region homologous to the stump in the intact leg in almost all amputees, when single subject fMRI data were analyzed. Group analysis, however, did not show S2 activation differences between amputees and controls. A single-case fMRI study (Condés-Lara et al., 2000) showed that a tactile stimulus on the stump in a lower limb, painless amputee produced an enlarged contralateral S1 cortical activation but only contralateral S2 activation, while stimulation of the intact leg induced bilateral S2 activations. These activations could be, as stated, related to new and compensatory functions.

In many individuals, phantom limb phenomena appear as early as $24 \mathrm{~h}$ after a traumatic amputation, and could be related to unmasking or reactivation of pre-existing connections, leading to suppression of local inhibition (Borsook et al., 1998; Ramachandran and Hirstein, 1998; Werhahn et al., 2002a; Giummarra et al., 2008). On the other hand, in some cases weeks or months were necessary before appearance of phantom sensations including pain (Pascual-Leone et al., 1996). Future studies directly comparing "painful" and "nonpainful" amputees will be need to explore the exact role and impact of phantom pain in somatosensory functional and structural brain reorganization.

\section{Structural changes in callosal connectivity of amputees}

Ramachandran and Hirstein (1998) suggested a multifactorial model to explain phantoms: they would depend on integrating experiences from remapping, peripheral inputs (i.e., stump neuromas), corollary discharges from motor commands to the limb, vivid somatic memories of the original limb and from genetically determined internal image of the body. In addition, the role of transcallosal cross-referencing between phantom and intact limb has recently gained importance, related to changes in commissural connections. These interhemispheric pathways contribute to bimanual coordination and recruit inhibitory circuits for unimanual movements (Carson, 2005). Probably, the same is true for bipedal control. Indeed, we observed that in most cases, our activations of S1 and M1 contralateral to amputation led to activation of homotopic areas ipsilateral to amputation as well that could be related to changes in callosal connections in amputees. 
To approach this issue, we used DTI, which enables a detailed assessment of fiber tract orientation, and provides information about microstructural tissue integrity in both white and gray matter (Ciccarelli et al., 2001; Hagmann et al., 2006). High fractional anisotropy values from the presumed callosal somatosensory region would reflect an increased or more organized connectivity related to the tissue microstructure, such as degree of myelination, axonal diameter, and density and coherence in fiber orientation (Basser, 1995; Basser and Pierpaoli, 1996; Pierpaoli and Basser, 1996). A previous report, combining TMS and DTI, has demonstrated that FA values of the corpus callosum are positively correlated with the degree of interhemispheric inhibition in a group of controls (Wahl et al., 2007). In our study, amputees showed decreased FA in the body of the corpus callosum compared with controls, which could be related to a less organized connectivity and thus to decreased interhemispheric inhibition through that pathway following amputation. Decreased cortical inhibition may be mediated through excitatory callosal neurons, which act on local GABAergic neurons (Garraghty et al., 1991; 2006; Irlbacher et al., 2007).

Unmasking of synapses and removal of local inhibition or cross-referencing of limbs have been implicated in phantom limb phenomena, but structural changes cannot be discarded (Elbert and Rockstroh, 2004). In this context, our study is the first to report structural abnormalities in callosal connectivity after amputation of a lower limb. The use of fiber reconstruction and tracking with probabilistic tractography demonstrated asymmetries or displacement of the topographic fiber terminations in the deafferented hemisphere, as well as in the opposite, putatively normal hemisphere. Interestingly, a previous study using TMS mapping also reported a lateral displacement of the functional map in the cortex ipsilateral to amputation (Elbert and Rockstroh, 2004). This effect may indicate a reorganization of the intact leg cortical representation, possibly mediated by its increased/abnormal use, in agreement with the view that WM structure is influenced by use, a phenomenon described as "input increase" reorganization (Elbert and Rockstroh, 2004). Our connectivity data support this view, in line with the observed displacement of fiber terminations on the hemisphere contralateral to the intact leg. Despite this attractive hypothesis, reorganization due to transcallosal interactions from the deafferented to the homologous somatosensory and motor cortex is also likely to be involved (Schwenkreis et al., 2001, 2003).

\section{References}

Arcadi JA (1977) "Phantom bladder": is this an unusual entity? J Urol 118:354-355.

Basser PJ (1995) Inferring microstructural features and the physiological state of tissues from diffusion-weighted images. NMR Biomed 8:333-344.

Basser PJ, Pierpaoli C (1996) Microstructural and physiological features of tissues elucidated by quantitative-diffusion-tensor MRI. J Magn Reson B 111:209-219.

Behrens TE, Berg HJ, Jbabdi S, Rushworth MF, Woolrich MW (2007) Probabilistic diffusion tractography with multiple fibre orientations: What can we gain? Neuroimage 34:144-155.

Benner T, van der Kouwe AJ, Kirsch JE, Sorensen AG (2006) Real-time RF pulse adjustment for B0 drift correction. Magn Reson Med 56:204-209.

Birbaumer N, Lutzenberger W, Montoya P, Larbig W, Unertl K, Töpfner S, Grodd W, Taub E, Flor H (1997) Effects of regional anesthesia on phantom limb pain are mirrored in changes in cortical reorganization. J Neurosci 17:5503-5508.

Björkman B, Arnér S, Hydén LC (2008) Phantom breast and other syndromes after mastectomy: eight breast cancer patients describe their experiences over time: a 2-year follow-up study. J Pain 9:1018-1025.

Borsook D, Becerra L, Fishman S, Edwards A, Jennings CL, Stojanovic M, Papinicolas L, Ramachandran VS, Gonzalez RG, Breiter H (1998) Acute plasticity in the human somatosensory cortex following amputation. Neuroreport 9:1013-1017.

Buonomano DV, Merzenich MM (1998) Cortical plasticity: from synapses to maps. Annu Rev Neurosci 21:149-186.

Carson RG (2005) Neural pathways mediating bilateral interactions between the upper limbs. Brain Res Brain Res Rev 49:641-662.

Casale R, Alaa L, Mallick M, Ring H (2009) Phantom limb related phenomena and their rehabilitation after lower limb amputation. Eur J Phys Rehabil Med 45:559-566.

Chahine L, Kanazi G (2007) Phantom limb syndrome: a review. Middle East J Anesthesiol 19:345-355.

Chen R, Corwell B, Yaseen Z, Hallett M, Cohen LG (1998) Mechanisms of cortical reorganization in lower-limb amputees. J Neurosci 18:3443-3450.

Chen R, Cohen LG, Hallett M (2002) Nervous system reorganization following injury. Neuroscience 111:761-773.

Ciccarelli O, Werring DJ, Wheeler-Kingshott CA, Barker GJ, Parker GJ, Thompson AJ, Miller DH (2001) Investigation of MS normal-appearing brain using diffusion tensor MRI with clinical correlations. Neurology 56:926-933.

Cohen LG, Bandinelli S, Findley TW, Hallett M (1991) Motor reorganization after upper limb amputation in man. A study with focal magnetic stimulation. Brain 114:615-627.

Condés-Lara M, Barrios FA, Romo JR, Rojas R, Salgado P, Sánchez-Cortazar J (2000) Brain somatic representation of phantom and intact limb: a fMRI study case report. Eur J Pain 4:239-245.

Curt A, Yengue CN, Hilti LM, Brugger P (2011) Supernumerary phantom limbs in spinal cord injury. Spinal Cord 49:588-595.

Darian-Smith C, Brown S (2000) Functional changes at periphery and cortex following dorsal root lesions in adult monkeys. Nat Neurosci 3: 476-481.

Dettmers C, Adler T, Rzanny R, van Schayck R, Gaser C, Weiss T, Miltner WH, Brückner L, Weiller C (2001) Increased excitability in the primary motor cortex and supplementary motor area in patients with phantom limb pain after upper limb amputation. Neurosci Lett 307:109-112.

Diers M, Christmann C, Koeppe C, Ruf M, Flor H (2010) Mirrored, imagined and executed movements differentially activate sensorimotor cortex in amputees with and without phantom limb pain. Pain 149:296-304.

Doetsch GS (1997) Progressive changes in cutaneous trigger zones for sensation referred to a phantom hand: a case report and review with implications for cortical reorganization. Somatosens Mot Res 14:6-16.

Donoghue JP, Suner S, Sanes JN (1990) Dynamic organization of primary motor cortex output to target muscles in adult rats. II. Rapid reorganization following motor nerve lesions. Exp Brain Res 79:492-503.

Dorpat TL (1971) Phantom sensation of internal organs. Compr Psychiatry $12: 27-35$

Elbert T, Rockstroh B (2004) Reorganization of human cerebral cortex: the range of changes following use and injury. Neuroscientist 10:129-141.

Flor H (2002) Phantom-limb pain: characteristics, causes, and treatment. Lancet Neurol 1:182-189.

Flor H (2003) Cortical reorganisation and chronic pain: implications for rehabilitation. J Rehabil Med [Suppl 41]:66-72.

Flor H, Elbert T, Knecht S, Wienbruch C, Pantev C, Birbaumer N, Larbig W, Taub E (1995) Phantom-limb pain as a perceptual correlate of cortical reorganization following arm amputation. Nature 375:482-484.

Flor H, Elbert T, Mühlnickel W, Pantev C, Wienbruch C, Taub E (1998) Cortical reorganization and phantom phenomena in congenital and traumatic upper-extremity amputees. Exp Brain Res 119:205-212.

Flor H, Mühlnickel W, Karl A, Denke C, Grüsser S, Kurth R, Taub E (2000) A neural substrate for nonpainful phantom limb phenomena. Neuroreport 11:1407-1411.

Flor H, Nikolajsen L, Staehelin Jensen T (2006) Phantom limb pain: a case of maladaptive CNS plasticity? Nat Rev Neurosci 7:873-881.

Florence SL, Kaas JH (1995) Large-scale reorganization at multiple levels of the somatosensory pathway follows therapeutic amputation of the hand in monkeys. J Neurosci 15:8083-8095.

Friston KJ, Holmes AP, Poline JB, Grasby PJ, Williams SC, Frackowiak RS, Turner R (1995) Analysis of fMRI time-series revisited. Neuroimage 2:45-53.

Garraghty PE, LaChica EA, Kaas JH (1991) Injury-induced reorganization of somatosensory cortex is accompanied by reductions in GABA staining. Somatosens Mot Res 8:347-354. 
Garraghty PE, Arnold LL, Wellman CL, Mowery TM (2006) Receptor autoradiography correlates of deafferentation-induced reorganization in adult primate somatosensory cortex. J Comp Neurol 497:636-645.

Giraux P, Sirigu A, Schneider F, Dubernard JM (2001) Cortical reorganization in motor cortex after graft of both hands. Nat Neurosci 4:691-692.

Giummarra MJ, Gibson SJ, Georgiou-Karistianis N, Bradshaw JL (2007) Central mechanisms in phantom limb perception: the past, present and future. Brain Res Rev 54:219-232.

Giummarra MJ, Gibson SJ, Georgiou-Karistianis N, Bradshaw JL (2008) Mechanisms underlying embodiment, disembodiment and loss of embodiment. Neurosci Biobehav Rev 32:143-160.

Grüsser SM, Winter C, Mühlnickel W, Denke C, Karl A, Villringer K, Flor H (2001) The relationship of perceptual phenomena and cortical reorganization in upper extremity amputees. Neuroscience 102:263-272.

Grüsser SM, Mühlnickel W, Schaefer M, Villringer K, Christmann C, Koeppe C, Flor H (2004) Remote activation of referred phantom sensation and cortical reorganization in human upper extremity amputees. Exp Brain Res 154:97-102.

Hagmann P, Jonasson L, Maeder P, Thiran JP, Wedeen VJ, Meuli R (2006) Understanding diffusion MR imaging techniques: from scalar diffusionweighted imaging to diffusion tensor imaging and beyond. Radiographics 26 [Suppl 1]:S205-S223.

Hamzei F, Liepert J, Dettmers C, Adler T, Kiebel S, Rijntjes M, Weiller C (2001) Structural and functional cortical abnormalities after upper limb amputation during childhood. Neuroreport 12:957-962.

Hofer S, Frahm J (2006) Topography of the human corpus callosum revisited-comprehensive fiber tractography using diffusion tensor magnetic resonance imaging. Neuroimage 32:989-994.

Irlbacher K, Brocke J, Mechow JV, Brandt SA (2007) Effects of GABA(A) and $\operatorname{GABA}(\mathrm{B})$ agonists on interhemispheric inhibition in man. Clin Neurophysiol 118:308-316.

Jiang H, van Zijl PC, Kim J, Pearlson GD, Mori S (2006) DtiStudio: resource program for diffusion tensor computation and fiber bundle tracking. Comput Methods Programs Biomed 81:106-116.

Juliano SL, Ma W, Eslin D (1991) Cholinergic depletion prevents expansion of topographic maps in somatosensory cortex. Proc Natl Acad Sci U S A $88: 780-784$

Kaas JH (1983) What, if anything, is SI? Organization of first somatosensory area of cortex. Physiol Rev 63:206-231.

Kaas JH (1991) Plasticity of sensory and motor maps in adult mammals. Annu Rev Neurosci 14:137-167.

Karl A, Birbaumer N, Lutzenberger W, Cohen LG, Flor H (2001) Reorganization of motor and somatosensory cortex in upper extremity amputees with phantom limb pain. J Neurosci 21:3609-3618.

Knecht S, Henningsen H, Höhling C, Elbert T, Flor H, Pantev C, Taub E (1998) Plasticity of plasticity? Changes in the pattern of perceptual correlates of reorganization after amputation. Brain 121:717-724.

Lotze M, Grodd W, Birbaumer N, Erb M, Huse E, Flor H (1999) Does use of a myoelectric prosthesis prevent cortical reorganization and phantom limb pain? Nat Neurosci 2:501-502.

Lotze M, Flor H, Grodd W, Larbig W, Birbaumer N (2001) Phantom movements and pain. An fMRI study in upper limb amputees. Brain 124:2268-2277.

Macey PM, Macey KE, Kumar R, Harper RM (2004) A method for removal of global effects from fMRI time series. Neuroimage 22:360-366.

MacIver K, Lloyd DM, Kelly S, Roberts N, Nurmikko T (2008) Phantom limb pain, cortical reorganization and the therapeutic effect of mental imagery. Brain 131:2181-2191.

Marbach JJ (1978) Phantom tooth pain. J Endod 4:362-372.

Melzack R (1990) Phantom limbs and the concept of a neuromatrix. Trends Neurosci 13:88-92.

Melzack R (1999) From the gate to the neuromatrix. Pain [Suppl 6]:S121-S126

Mercier C, Reilly KT, Vargas CD, Aballea A, Sirigu A (2006) Mapping phantom movement representations in the motor cortex of amputees. Brain 129:2202-2210

Merzenich MM, Jenkins WM (1993) Reorganization of cortical representations of the hand following alterations of skin inputs induced by nerve injury, skin island transfers, and experience. J Hand Ther 6:89-104.

Merzenich MM, Nelson RJ, Stryker MP, Cynader MS, Schoppmann A, Zook JM (1984) Somatosensory cortical map changes following digit amputation in adult monkeys. J Comp Neurol 224:591-605.
Montoya P, Larbig W, Grulke N, Flor H, Taub E, Birbaumer N (1997) The relationship of phantom limb pain to other phantom limb phenomena in upper extremity amputees. Pain 72:87-93.

Montoya P, Ritter K, Huse E, Larbig W, Braun C, Töpfner S, Lutzenberger W, Grodd W, Flor H, Birbaumer N (1998) The cortical somatotopic map and phantom phenomena in subjects with congenital limb atrophy and traumatic amputees with phantom limb pain. Eur J Neurosci 10:1095-1102.

Nichols TE, Holmes AP (2002) Nonparametric permutation tests for functional neuroimaging: a primer with examples. Hum Brain Mapp 15:1-25.

Nicolelis MA, Lin RC, Woodward DJ, Chapin JK (1993) Induction of immediate spatiotemporal changes in thalamic networks by peripheral block of ascending cutaneous information. Nature 361:533-536.

Ovesen P, Krøner K, Ornsholt J, Bach K (1991) Phantom-related phenomena after rectal amputation: prevalence and clinical characteristics. Pain 44:289-291.

Pajevic S, Pierpaoli C (1999) Color schemes to represent the orientation of anisotropic tissues from diffusion tensor data: application to white matter fiber tract mapping in the human brain. Magn Reson Med 42:526-540.

Pascual-Leone A, Peris M, Tormos JM, Pascual AP, Catalá MD (1996) Reorganization of human cortical motor output maps following traumatic forearm amputation. Neuroreport 7:2068-2070.

Pierpaoli C, Basser PJ (1996) Toward a quantitative assessment of diffusion anisotropy. Magn Reson Med 36:893-906.

Pons TP, Garraghty PE, Mishkin M (1988) Lesion-induced plasticity in the second somatosensory cortex of adult macaques. Proc Natl Acad Sci U S A 85:5279-5281.

Pons TP, Garraghty PE, Ommaya AK, Kaas JH, Taub E, Mishkin M (1991) Massive cortical reorganization after sensory deafferentation in adult macaques. Science 252:1857-1860.

Pühse G, Wachsmuth JU, Kemper S, Husstedt IW, Kliesch S, Evers S (2010) Phantom testis syndrome: prevalence, phenomenology and putative mechanisms. Int J Androl 33:e216-e220.

Qi HX, Chen LM, Kaas JH (2011) Reorganization of somatosensory cortical areas $3 \mathrm{~b}$ and 1 after unilateral section of dorsal columns of the spinal cord in squirrel monkeys. J Neurosci 31:13662-13675.

Ramachandran VS (1993) Behavioral and magnetoencephalographic correlates of plasticity in the adult human brain. Proc Natl Acad Sci U S A 90:10413-10420.

Ramachandran VS, Hirstein W (1998) The perception of phantom limbs. The D. O. Hebb lecture. Brain 121:1603-1630.

Ramachandran VS, Rogers-Ramachandran D (2000) Phantom limbs and neural plasticity. Arch Neurol 57:317-320.

Ramachandran VS, Rogers-Ramachandran D, Stewart M (1992) Perceptual correlates of massive cortical reorganization. Science 258:1159-1160.

Reilly KT, Sirigu A (2008) The motor cortex and its role in phantom limb phenomena. Neuroscientist 14:195-202.

Röricht S, Meyer BU, Niehaus L, Brandt SA (1999) Long-term reorganization of motor cortex outputs after arm amputation. Neurology 53:106-111.

Rueckert D, Sonoda LI, Hayes C, Hill DL, Leach MO, Hawkes DJ (1999) Nonrigid registration using free-form deformations: application to breast MR images. IEEE Trans Med Imaging 18:712-721.

Sanes JN, Suner S, Donoghue JP (1990) Dynamic organization of primary motor cortex output to target muscles in adult rats. I. Long-term patterns of reorganization following motor or mixed peripheral nerve lesions. Exp Brain Res 79:479-491.

Schwenkreis P, Witscher K, Janssen F, Pleger B, Dertwinkel R, Zenz M, Malin JP, Tegenthoff M (2001) Assessment of reorganization in the sensorimotor cortex after upper limb amputation. Clin Neurophysiol 112:627-635

Schwenkreis P, Pleger B, Cornelius B, Weyen U, Dertwinkel R, Zenz M, Malin JP, Tegenthoff M (2003) Reorganization in the ipsilateral motor cortex of patients with lower limb amputation. Neurosci Lett 349:187-190.

Simonyan K, Tovar-Moll F, Ostuni J, Hallett M, Kalasinsky VF, Lewin-Smith MR, Rushing EJ, Vortmeyer AO, Ludlow CL (2008) Focal white matter changes in spasmodic dysphonia: a combined diffusion tensor imaging and neuropathological study. Brain 131:447-459.

Smith SM (2002) Fast robust automated brain extraction. Hum Brain Mapp $17: 143-155$

Smith SM, Jenkinson M, Woolrich MW, Beckmann CF, Behrens TE, Johansen-Berg H, Bannister PR, De Luca M, Drobnjak I, Flitney DE, Niazy RK, Saunders J, Vickers J, Zhang Y, De Stefano N, Brady JM, Mat- 
thews PM (2004) Advances in functional and structural MR image analysis and implementation as FSL. Neuroimage 23 [Suppl 1]:S208-S219.

Smith SM, Jenkinson M, Johansen-Berg H, Rueckert D, Nichols TE, Mackay CE, Watkins KE, Ciccarelli O, Cader MZ, Matthews PM, Behrens TE (2006) Tract-based spatial statistics: voxelwise analysis of multi-subject diffusion data. Neuroimage 31:1487-1505.

Sörös P, Vo O, Husstedt IW, Evers S, Gerding H (2003) Phantom eye syndrome: its prevalence, phenomenology, and putative mechanisms. Neurology 60:1542-1543.

Staps T, Hoogenhout J, Wobbes T (1985) Phantom breast sensations following mastectomy. Cancer 56:2898-2901.

Tanaka H, Arai M, Kadowaki T, Takekawa H, Kokubun N, Hirata K (2008) Phantom arm and leg after pontine hemorrhage. Neurology 70:82-83.

Tovar-Moll F, Evangelou IE, Chiu AW, Richert ND, Ostuni JL, Ohayon JM, Auh S, Ehrmantraut M, Talagala SL, McFarland HF, Bagnato F (2009) Thalamic involvement and its impact on clinical disability in patients with multiple sclerosis: a diffusion tensor imaging study at 3T. AJNR Am J Neuroradiol 30:1380-1386.

Vargas CD, Aballéa A, Rodrigues EC, Reilly KT, Mercier C, Petruzzo P, Dubernard JM, Sirigu A (2009) Re-emergence of hand-muscle representations in human motor cortex after hand allograft. Proc Natl Acad Sci U S A 106:7197-7202.

Wahl M, Lauterbach-Soon B, Hattingen E, Jung P, Singer O, Volz S, Klein JC, Steinmetz H, Ziemann U (2007) Human motor corpus callosum: topography, somatotopy, and link between microstructure and function. J Neurosci 27:12132-12138.

Werhahn KJ, Mortensen J, Kaelin-Lang A, Boroojerdi B, Cohen LG (2002a) Cortical excitability changes induced by deafferentation of the contralateral hemisphere. Brain 125:1402-1413.

Werhahn KJ, Mortensen J, Van Boven RW, Zeuner KE, Cohen LG (2002b) Enhanced tactile spatial acuity and cortical processing during acute hand deafferentation. Nat Neurosci 5:936-938.

Worsley KJ, Friston KJ (1995) Analysis of fMRI time-series revisitedagain. Neuroimage 2:173-181.

Wu CW, Kaas JH (2000) Spinal cord atrophy and reorganization of motoneuron connections following long-standing limb loss in primates. Neuron 28:967-978.

Xerri C, Merzenich MM, Jenkins W, Santucci S (1999) Representational plasticity in cortical area $3 \mathrm{~b}$ paralleling tactual-motor skill acquisition in adult monkeys. Cereb Cortex 9:264-276. 